Webology, Volume 17, Number 1, June, 2020

\begin{tabular}{|l|l|l|l|}
\hline Home & Table of Contents & Titles \& Subject Index & Authors Index \\
\hline
\end{tabular}

\title{
Presenting a Conceptual Model of Adopting Micro-Blogging in Learning
}

\section{Mohmmadhiwa Abdekhoda}

Associate Professor, Department of Medical Library and Information Sciences, School of Health Management and Medical Informatics, Tabriz University of Medical Sciences. Iranian Center of Excellence in Health Management (ICEHM), School of Management and Medical Informatics, Tabriz University of Medical Sciences, Tabriz, Iran. ORCID: 0000-0002-1797-8916. E-mail: hiwaabdekhoda@gmail.com

\section{Asgar Sattari*}

*Corresponding Author, MSc. of Medical Library and Information Sciences. School of Health Management and Medical Informatics. Tabriz University of Medical Sciences. Tabriz, Iran. E-mail: asgarsattari123@gmail.com

\section{Masoud Mohammadi}

Golestan Research Center of Gastroenterology and Hepatology, Golestan University of Medical Sciences, Gorgan, Iran. ORCID: 0000-0001-9874-3045. E-mail: mohammadi@goums.ac.ir

PhD Candidate in Medical Library and Information Science, Tehran University of Medical Sciences, Tehran, Iran.

\section{Kawa Mirza Salih}

MA, Assistant instructor, English Department, Charmo University, Sulaimani, Iraq. ORCID: 0000-0001-6595-3433. E-mail: kawa.mirza@charmouniversity.org

Received December 22, 2019; Accepted June 20, 2020 


\begin{abstract}
Platforms like information sharing, disseminating and acquiring based on users transactions are provided by Microblogging sites. Nowadays microblogs are the main tools for people to send their opinions to relatives, friends or the world quickly. This paper uses the Theory of planned behavior to investigate and explain Tabriz University of Medical Sciences (TUOMS) students' acceptance of Microblogging. A questionnaire was applied to collect data from students of TUOMS' University, and the data were analyzed by SPSS V.16. After analysis, the results demonstrate that Attitude toward the Behavior, Subjective Norms and Perceived Behavioral Control has positive effects on behavioral intentions, and behavioral intentions also have positive effects on user behavior. Overall, if students believe that Microblogging can help them increase their Attitude toward the Behavior and their control, there is an increase in their intention to use them. The findings of the study shall be useful to curriculum developers, Microblogging practitioners, and educational policymakers.
\end{abstract}

\title{
Keywords
}

Microblogging; Electronic learning; Health education; Theory of planned behavior

\section{Introduction}

Platforms like information sharing, disseminating and acquiring based on users transactions are provided by Microblogging sites. It is a kind of blogging which is used for purposes such as allowing the users to write short texts and even publish them (mostly 140 letters) for public view and even being viewed by limited groups which the user had chosen. Microblogging allows the user to exchange entities such as short texts and files which contain small size. They absorbed a vast variety of people in recent few years. For instance, Twitter, Jaiku and more recently Pownce (Johnson, Donohue, Atkin, \& Johnson, 1994; Kraut, Fish, Root, \& Chalfonte, 1990). Scientists have found microblogs as a new education method due to the fast growth of users (Li \& Shiu, 2012). As it comes to universities these institutes can establish their relationship with students and attract them through these information systems (Hsu, Park et al. 2013). The usage of social media has transformed from being used unofficially being educational matters to a formal and official usage by students, faculties, and administrators. This has happened due to the common nature of social media which is being used frequently and its pervasive information utilization. Due to the acceptance of Twitter as one of the microblogging applications, a massive number of self-standing twits became available to convey educational communities' intentions.

Users can express and read microblogging documents on a different platform and modality nonstandard textual drafts, and informal language are results of this briefness. It is easier to disseminate information by microblogs than blogs. Due to shortness of microblogging posts, 
users can publish their thoughts instantly via an electronic device such as Smartphones. Nowadays microblogs are the main tools for people to send their opinions to relatives, friends or the world quickly (Yang, 2012). This kind of education provides services for students as one the most advanced methods of education in contemporary world which it has achieved by utilizing advanced technologies such as Internet networks, Intranet, database, knowledge managing, and information managing.

Electronic learning in universities of Iran including Tabriz University of Medical Sciences (TUOMS) is being done by the Education Development Center. These centers are for education and research which were created in 1990 under the supervision of the ministry of health and the main purpose was improving quality of education. Right now most of the faculties of Tabriz University of Medical Sciences have E-learning courses for their lessons.

\section{Theory of Planned Behavior}

The Theory of Planned Behavior (TPB) is a framework which, formerly referred to as "Theory of Reasoned Action (TRA)", was first suggested by Fishbein (1967) as a tool to relate behavior, behavioral intention, attitudes, and beliefs. In this framework, the influential factors on intentions which lead to a specific behavior are taken into account (Ajzen, 2002). Looking from the point of view of the authors of this theory, the most important factor in determining an individual's behavior is their "behavioral intention". The signification of Behavioral intention is "the token of a person's intention to do a behavior". The easiest way to determine whether or not a person is intended to do a specific behavior or not is to simply ask him/her. Regarding Fishbone et al. the probability of doing a behavior by an individual is affected by two factors: a persons' attitude toward the behavior and his/her subjective Norms. Hence, this theory considers the existence of a direct relation between behavioral intention and subjective Norms and attitudes of the individual towards that behavior. Where there is a full intentional control of the behavior and all its conditions, the usage of TRA is possible. However, in some cases, the usage of this theory is limited, where the intentional control decreases and regardless of the fact that the individual has behavioral intention he/she is not able to do that behavior. In such cases, the level of control on the conditions of the behavior becomes important. Moreover, a difficulty level of the behavior would become an influencing factor on behavioral intention (Taylor \& Todd, 1995).

Taking such discrepancies into consideration, Ajzen et al. introduced the third construct namely "Perceived Control" and suggested the "Theory of Planned Behavior". This third factor was added to the two factors already available in theory of reasoned action and is related to presence or absence of barriers in a performance of behaviors and influence of each situation in difficulty level of performance of a behavior. Therefore, TPB is the extended form of TRA. In this theory, three constructs are to be measured: "attitude toward the behavior", "subjective Norms", and "perceived behavior control", then their relation to behavioral intention should be determined 
and the suitable intervention can be then planned. It should be taken into consideration that the weights of these factors in different societies and different behaviors are not the same(Ajzen, 2002). Therefore, the purpose of this study is to validate the Microblogging Acceptance on a sample of university students from a different faculty of Tabriz University of Medical Sciences (TUOMS). In this study, six hypotheses are proposed, as follows:

1. Attitude toward the Behavior (ATB) will have a direct effect on the students' Subjective Norms (SN) to use microblogs.

2. Subjective Norms (SN) will have a direct effect on the students' Perceived Behavioral Control (PBC) to use microblogs.

3. Attitude toward the Behavior (ATB) will have a direct effect on the students' Intentions to use microblogs.

4. Subjective Norms (SN) will have a direct effect on the students' Intentions to use microblogs.

5. Perceived Behavioral Control (PBC) will have a direct effect on the students' Intentions to use microblogs.

6. The intention will have a direct effect on the students' Behavior to use microblogs.

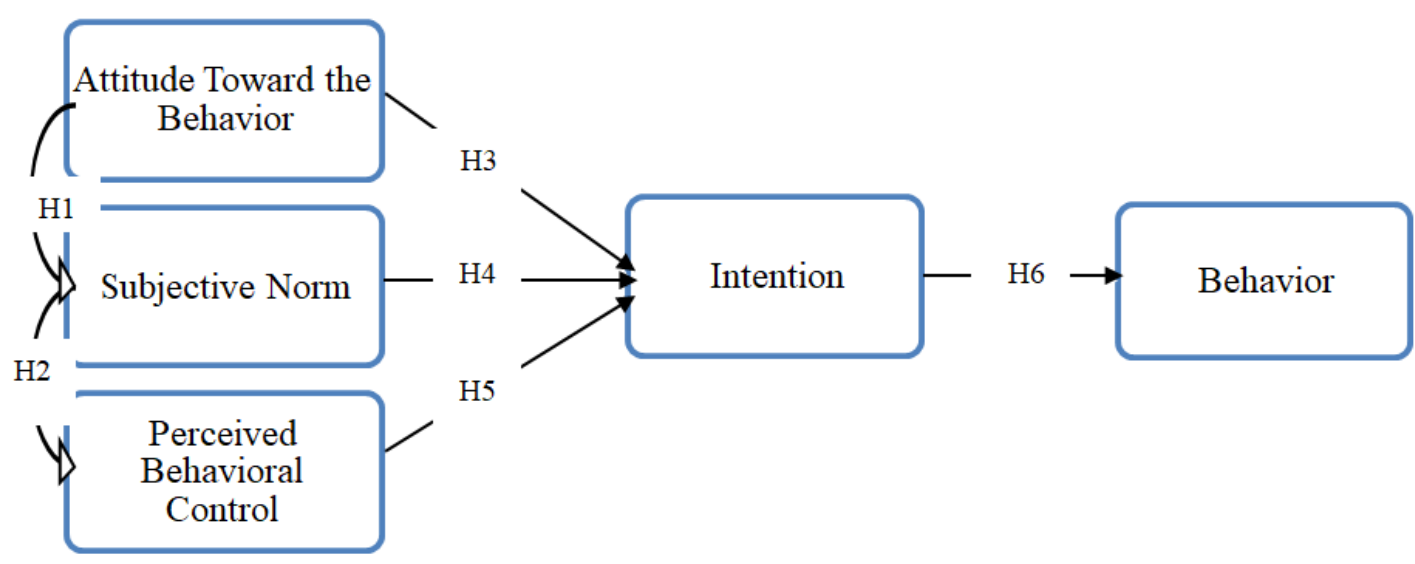

Figure 1. The proposed conceptual model for Microblogging Acceptance

\section{Materials and Methods}

This research used Quantitative approach for the collection and analysis of data by conducting surveys and questionnaires from related participants to investigate the factors that impact the acceptance of microblogging use in Tabriz University of Medical Sciences (TUOMS). Students from different disciplines were selected to participate in this study based on their availability the researcher during the study term.

We developed a questionnaire on the basis of constructs' measurements, which have been adopted in previous studies (Abdekhoda, Ahmadi, Dehnad, \& Hosseini, 2014; Abdekhoda, Ahmadi, Dehnad, Noruzi, \& Gohari, 2016; Ajzen, 2002; Sattari, Abdekhoda, \& Gavgani, 2017). 
The items used in this study were the 6-factor, 21 item microblogging Acceptance Measure. The instrument consists of six factors; Attitude toward the Behavior, Subjective Norms, Perceived behavioral control, Behavioral Intention, Functional planning, and Behavior. These items were presented using a 5-point Likert response scale, ranging from 1 - strongly agree to 5- strongly disagree.

Each factor in the questionnaire showed that Cronbach's $\alpha$ was higher than .8 , indicating a good internal consistency among items in each factor. The factor loading for each item (i.e., measuring variable) was greater than .6, meaning an adequate individual reliability for each item. After gathering Data, they were entered in the SPSS software program to analyze them, factor analysis and descriptive statistics items (mean mode, frequency, percentage, and standard deviation) and inferential statistics (Spearman correlation coefficient and regression) were used.

Table 1. Items used to measure the various constructs in the integrated model

\begin{tabular}{|c|c|c|}
\hline Construct & Item Number & Items \\
\hline \multirow{4}{*}{$\begin{array}{l}\text { Attitude } \\
\text { Toward the } \\
\text { Behavior }\end{array}$} & 1 & Accomplish of educational activity by microblogging is helpful for me. \\
\hline & 2 & Utilization of educational activity by microblogging is effective for me. \\
\hline & 3 & Accomplish of educational activity by microblogging is wisely for me. \\
\hline & 4 & I feel relaxed as using microblogging. \\
\hline \multirow{4}{*}{$\begin{array}{l}\text { Subjective } \\
\text { Norms }\end{array}$} & 5 & $\begin{array}{l}\text { Most of the people being important in my life to think I should accomplish } \\
\text { educational activity by microblogging. }\end{array}$ \\
\hline & 6 & $\begin{array}{l}\text { Most of the people being important in my life to ask me to accomplish } \\
\text { educational activity by microblogging. }\end{array}$ \\
\hline & 7 & $\begin{array}{l}\text { Most of the people being important in my life to accomplish educational activity } \\
\text { by microblogging. }\end{array}$ \\
\hline & 8 & $\begin{array}{l}\text { The educational system expects me to accomplish educational activity by } \\
\text { microblogging. }\end{array}$ \\
\hline \multirow{4}{*}{$\begin{array}{l}\text { Perceived } \\
\text { behavioral } \\
\text { control }\end{array}$} & 9 & It is easy for me to do an educational activity using microblogging. \\
\hline & 10 & While using microblogging, I have the complete mastery of the process. \\
\hline & 11 & The condition of commencing microblogging is easy to handle. \\
\hline & 12 & $\begin{array}{l}\text { Using microblogging for educational activity is easy for both their tutor and the } \\
\text { learner. }\end{array}$ \\
\hline \multirow{4}{*}{$\begin{array}{l}\text { Behavioral } \\
\text { Intention }\end{array}$} & 13 & The probability of using microblogging is high for me. \\
\hline & 14 & I am interested in having educational activity using microblogging in near future. \\
\hline & 15 & I have scheduled using microblogging in the future. \\
\hline & 16 & I anticipate using microblogging for an educational activity. \\
\hline \multirow{4}{*}{$\begin{array}{l}\text { Functional } \\
\text { planning }\end{array}$} & 17 & I have scheduled the time for doing an educational activity using microblogging. \\
\hline & 18 & $\begin{array}{l}\text { I have scheduled the place for doing an educational activity using } \\
\text { microblogging. }\end{array}$ \\
\hline & 19 & I have scheduled the item for doing an educational activity using microblogging. \\
\hline & 20 & $\begin{array}{l}\text { I scheduled a weekly program on how to use microblogging for educational } \\
\text { activity. }\end{array}$ \\
\hline \multirow{4}{*}{ Behavior } & 21 & I intend to use microblogging in the future. \\
\hline & 22 & I predict to achieve significant success in learning by using microblogging. \\
\hline & 23 & Doing educational activity using microblogging is part of my life plan. \\
\hline & 24 & I intend to achieve significant success in learning using microblogging. \\
\hline
\end{tabular}




\section{Results}

As illustrated in Table 2, in total, we obtained 240 valid responses for this research. Table 2 lists the respondents' demographic characteristics. As shown in Table 2, 49.2 percent were males, whereas 47.1 percent were females. Many of respondents aged from 18 to 33. 25.4 percent had B.S. degree, 27.1 percent B.S. degree, and 42.5 percent held a Ph.D. degree. Twenty one point 5 percent $(21.5 \%)$ of the respondents were from Rehabilitation faculty.

Table 2. Demographic information of the sample

\begin{tabular}{|c|c|c|c|}
\hline Demographics & Category & Freq. & Per. \\
\hline \multirow{4}{*}{ Sex } & Male & 118 & 49.2 \\
\hline & Female & 113 & 47.1 \\
\hline & Missing & 9 & 3.7 \\
\hline & Total & 240 & 100 \\
\hline \multirow{6}{*}{ Age } & $18-22$ & 68 & 28.3 \\
\hline & $23-28$ & 70 & 29.2 \\
\hline & $29-33$ & 48 & 20 \\
\hline & $32-38$ & 5 & 2.1 \\
\hline & Missing & 49 & 20.4 \\
\hline & Total & 240 & 100 \\
\hline \multirow{5}{*}{ Degree } & B.S. & 61 & 25.4 \\
\hline & M.S. & 65 & 27.1 \\
\hline & Ph.D. & 102 & 42.5 \\
\hline & Missing & 12 & 5 \\
\hline & Total & 240 & 100 \\
\hline \multirow{9}{*}{ faculty } & Medicine & 24 & 11 \\
\hline & Nursing and Midwifery & 20 & 9.1 \\
\hline & Health and Nutrition & 34 & 15.5 \\
\hline & Rehabilitation & 47 & 21.5 \\
\hline & Pharmacy & 33 & 15.1 \\
\hline & Dentistry & 23 & 10.5 \\
\hline & $\begin{array}{c}\text { Management and } \\
\text { Medical Informatics }\end{array}$ & 38 & 17.4 \\
\hline & Missing & 21 & 8.8 \\
\hline & Total & 240 & 100 \\
\hline
\end{tabular}

Results in Table 3 showed that there was a statistically significant and positive correlation between all TPB variables and the use of Microblogging. In this survey, user intention and behavior were dependent variables, whereas ATT, SN, and PBC were independent variables. 
Table 3. Correlation between the Variables of the Proposed Conceptual Path Model 1, 2, 3

\begin{tabular}{|c|c|c|c|c|c|}
\hline Constructs & ATT & SN & PBC & Intention & Behavior \\
\hline ATT & 1 & & & & \\
\hline SN & $0 / 477^{*}$ & 1 & & & \\
\hline PBC & $0 / 168^{*}$ & $0 / 189^{*}$ & 1 & & \\
\hline Intention & $0 / 437 * *$ & $0 / 299^{*}$ & $0 / 148^{*}$ & 1 & \\
\hline Behavior & $0 / 261 * *$ & $0 / 208^{*}$ & $0 / 47$ & $0 / 287 * *$ & 1 \\
\hline
\end{tabular}

1) ** P-value is significant at 0.01 levels.

2) * P-value is significant at 0.05 levels.

3) ATT: Attitude toward the Behavior; SN: Subjective Norms; PBC: Perceived

Behavioral Control; Behavior: Behavior of Microblogging Use

\section{Discussion}

In this study, pertaining factors in acceptance of microblogging at Tabriz University of medical science were analyzed. We have chosen a quantitative method with a close-ended questionnaire to obtain the answers regarding the topic being discussed. Results turn out that students of TUOMS' are willing to use such methods. These facts present that students tend to show interest in learning as they use it more.

Due to this study, it is concluded there is statistically relationship between Attitude toward the Behavior (ATB) and Subjective Norms (SN) toward use microblogs $(\beta=.477, \mathrm{p}<.001)$. According to the ATB and SN, our findings confirm those of other researchers (Chan, 2004; Taylor \& Todd, 1995; Karimy, Niknami, Heidarnia, \& Hajizadeh, 2012). The findings indicate that there is statistical significance between students' Subjective Norms (SN) and Perceived Behavioral Control (PBC) to use microblogs $(\beta=.189, \mathrm{p}<.001)$; and support the results of those of familiar studies (Taylor and Todd, 1995; Khechine, Lakhal, Pascot, \& Bytha, 2014).

According to the result of the present study, there is a statistical significant connection through the students' Attitude toward the Behavior (ATB) on the students' Intentions to use microblogs $(\beta=0.437, p=0.001)$. This finding confirms the prior findings of Kolvereid (1996) and (Autio, Keeley, Klofsten, Parker, \& Hay, 2001). This means that student expecting E-learning system as a user-friendly system; increase their intention to use it.

Assuming the students' Subjective Norms (SN) coupled with the Intentions, the standard coefficient of SN and intention was found to be (0.299) with a p-value of (0.001). The findings are in line with pioneers' research (e.g., Khechine et al., 2014; Tounés, 2006).

The findings indicate that there is statistical significance between students' Perceived Behavioral Control (PBC) and students' Intentions to use microblogs $(\beta=.189, \mathrm{p}<.001)$. These findings support the results of those of familiar studies (Bandura, 1986; Le Mare, Audet, \& Kurytnik, 2007), while do support the findings of the study conducted by Bae and Kang (2008). 
Assuming the students' intentions coupled with the behavior of use of microblogs, the standard coefficient of intentions and behavior of use of microblogs was found to be (0.287) with a pvalue of (0.001). This finding indicates that if students are persuaded that microblog is suitable to their course objective, they will apply; and Karimy, Taylor, and Sattari (Karimy et al., 2012; Sattari et al., 2017; Taylor \& Todd, 1995) have the same point of view toward discussed advantage. Figure 2 showed the resulting path coefficients of the proposed research model. Overall, all hypotheses were supported by the data.

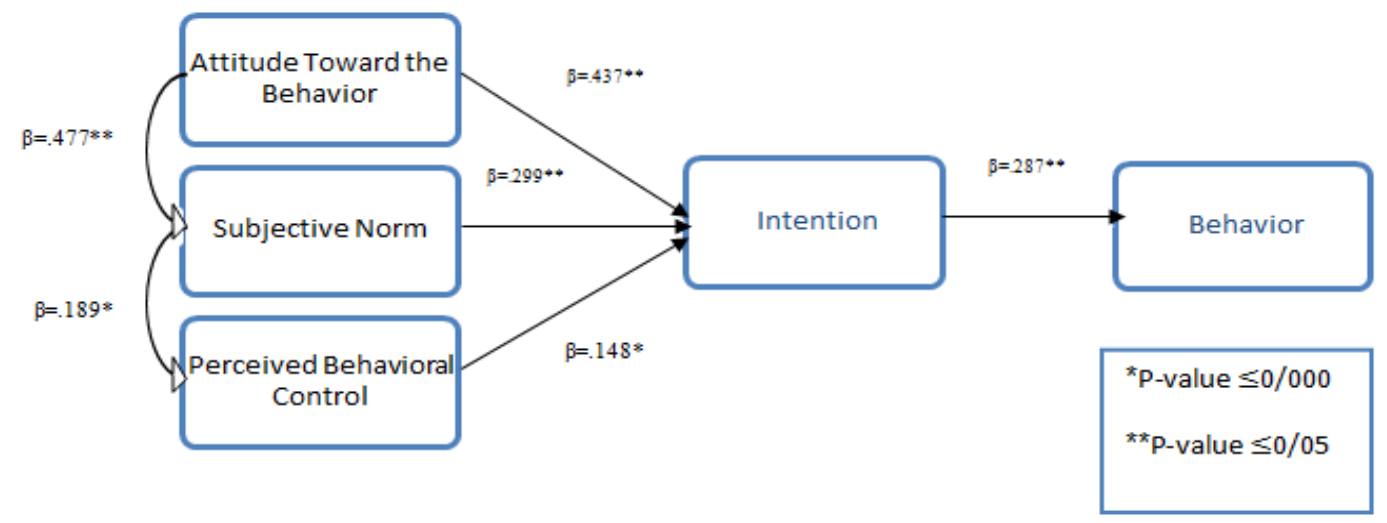

Figure 2. Path coefficients of the proposed research model

\section{Conclusion}

In this study, TUOMS' students were selected as our target sample to study the acceptance and use of microblogging by them. Its results have shown a high rate of technology acceptance among scholars which gave us more information about the pertaining factors encouraging students to use microblogging. Hence, the satisfaction of the users should be taken into consideration. It's verified that the meaningful correlation has been seen between behavioral intention and utilization of microblogging. Future studies could examine wider and different samples of students using various methods.

\section{Limitations}

Like other studies, this study had some limitations. Firstly, the impact of some factors such as individuals and cultural differences were not analyzed in our study. Secondly, the sample chosen from TUOMS' due to the limited number does not necessarily represent all the features of the society. Therefore, the results of this study cannot be generalized on large scale.

\section{Conflict of interest}

The authors declare no conflict of interest. 


\section{References}

Abdekhoda, M., Ahmadi, M., Dehnad, A., \& Hosseini, A. (2014). Information technology acceptance in health information management. Methods of information in medicine, 53(01), 14-20.

Abdekhoda, M., Ahmadi, M., Dehnad, A., Noruzi, A., \& Gohari, M. (2016). Applying electronic medical records in health care: Physicians' perspective. Applied clinical informatics, 7(2), 341.

Ajzen, I. (2002). Constructing a TPB questionnaire: Conceptual and methodological considerations.

Autio, E., Keeley, R. H., Klofsten, M., Parker, G.G.C., \& Hay, M. (2001). Entrepreneurial intent among students in Scandinavia and in the USA. Enterprise and Innovation Management Studies, 2(2), 145-160.

Bae, H.-S., \& Kang, S. (2008). The Influence of viewing an entertainment-education program on cornea donation intention: a test of the theory of planned behavior. Health Communication, 23(1), 87-95.

Bandura, A. (1986). Social foundations of thought and action: A social cognitive theory: Englewood Cliffs, NJ, US: Prentice-Hall, Inc.

Chan, S.-c. (2004). Understanding internet banking adoption and use behavior: A Hong Kong perspective. Journal of Global Information Management (JGIM), 12(3), 21-43.

Johnson, J. D., Donohue, W. A., Atkin, C. K., \& Johnson, S. (1994). Differences between formal and informal communication channels. The Journal of Business Communication (1973), 31(2), 111122.

Karimy, M., Niknami, S., Heidarnia, A., \& Hajizadeh, E. (2012). Psychometric properties of a theory of planned behavior questionnaire for tobacco use in male adolescents.

Khechine, H., Lakhal, S., Pascot, D., \& Bytha, A. (2014). UTAUT model for blended learning: The role of gender and age in the intention to use webinars. Interdisciplinary Journal of E-Learning and Learning Objects, 10(1), 33-52.

Kolvereid, L. (1996). Prediction of employment status choice intentions. Entrepreneurship Theory and practice, 21(1), 47-58.

Kraut, R. E., Fish, R. S., Root, R. W., \& Chalfonte, B. L. (1990). Informal communication in organizations: Form, function, and technology. Paper presented at the Human reactions to technology: Claremont symposium on applied social psychology.

Le Mare, L., Audet, K., \& Kurytnik, K. (2007). A longitudinal study of service use in families of children adopted from Romanian orphanages. International Journal of Behavioral Development, 31(3), 242-251.

Li, Y.-M., \& Shiu, Y.-L. (2012). A diffusion mechanism for social advertising over microblogs. Decision Support Systems, 54(1), 9-22. 
Sattari, A., Abdekhoda, M., \& Gavgani, V. Z. (2017). Determinant Factors Affecting the Web-based Training Acceptance by Health Students, Applying UTAUT Model. International Journal of Emerging Technologies in Learning (iJET), 12(10), 112-126.

Taylor, S., \& Todd, P. A. (1995). Understanding information technology usage: A test of competing models. Information systems research, 6(2), 144-176.

Tounés, A. (2006). L'intention entrepreneuriale des étudiants: le cas français. La revue des sciences de gestion(3), 57-65.

Yang, G. (2012). A Chinese Internet? History, practice, and globalization. Chinese Journal of Communication, 5(1), 49-54.

\section{Bibliographic information of this paper for citing:}

Abdekhoda, M., Sattari, A., Mohammadi, M., \& Salih, K. M. (2020). "Presenting a conceptual model of adopting micro-blogging in learning." Webology, 17(1), Article 210. Available at: http://www.webology.org/2020/v17n1/a210.pdf

Copyright (C) 2020, Mohmmadhiwa Abdekhoda, Asgar Sattari, Masoud Mohammadi and Kawa Mirza Salih. 